\title{
Gestational hyperglycaemia and insulin release by the fetal rat pancreas in vitro: effect of amino acids and glyceraldehyde
}

\author{
M. T. Bihoreau, A. Ktorza and L. Picon \\ Laboratoire de Physiologie du Développement associé au CNRS n 307 , Université Paris 7, Paris, France
}

\begin{abstract}
Summary. Unrestrained pregnant rats were infused with glucose during the last week of pregnancy to produce slight or high gestational hyperglycaemia. Control rats were infused with distilled water. Insulin secretion of the fetuses at term was studied in vitro using a perifusion system. Compared with controls, perifused pancreases of slightly hyperglycaemic fetuses showed a similar pattern of insulin secretion in response to $10 \mathrm{mmol} / 1$ leucine. Arginine-induced insulin secretion at $20 \mathrm{mmol} / 1$ was higher than in controls. In both groups, $10 \mathrm{mmol} / 1 \alpha$-ketoisocaproate had a poor stimulatory effect on insulin release, and $5 \mathrm{mmol} / 1 \mathrm{D}$-glyceraldehyde was ineffective in eliciting insulin secretion. In highly hyperglycaemic fetuses all the secretagogues, with the exception of arginine,
\end{abstract}

which induced a sustained monophasic insulin secretory response, had no effect on insulin release. These data show that long-term exposure of fetal B cells to high plasma glucose levels in utero suppresses or alters further insulin secretory response not only to glucose but also to other nutrient secretagogues. The partially spared insulin secretory response to arginine suggests that the defect may concern stimulus-secretion coupling rather than insulin releasing machinery.

Key words: Slight gestational hyperglycaemia, high gestational hyperglycaemia, fetus, insulin release, perifused pancreas, leucine, arginine.
Many investigators have reported that insulin secretion in response to glucose is, when detected, lower in fetal and neonatal than adult stages in man $[1,2]$ and the rat [3-5]. Despite immaturity of fetal islets compared with adult islets, evidence indicates that insulin release by fetal pancreases is sensitive to long-term plasma glucose changes in late pregnancy. This is clearly demonstrated in the infants of diabetic women $[1,6,7]$ and in fetuses at term from rats with streptozotocin-induced diabetes [5]. However, quite different effects on the fetal pancreatic function have been observed according to the severity of maternal diabetes $[5,8]$. In a previous study, we showed that the level of gestational hyperglycaemia, independent of other metabolic disorders usually associated with diabetes, was of crucial importance in the insulin secretory response by the fetal pancreas; moderate gestational hyperglycaemia led to an increase of insulinaemia which was not observed in highly hyperglycaemic fetuses [9].

It seems of interest to assess (a) whether impaired glucose-induced insulin secretion in severely hyperglycaemic fetuses may be ascribed to altered glucose metabolism in the islet; and (b) whether differential effects of gestational hyperglycaemia on insulin secretion are specific to glucose and glucose metabolism or can be extended to other secretagogues. We have studied insulin release by pancreases of slightly or highly hyperglycaemic fetuses in response to the following secretagogues in vitro: D-glyceraldehyde, which enters glycolysis distal to glucose at the triose phosphate stage; amino acids, which either are metabolized (leucine) [10] or are not metabolized (arginine) by the islet [11].

This study was performed using a perifusion system, which allows the evaluation of insulin secretory dynamics induced by a secretagogue free of environmental interferences. The perifusion system is more convenient than static incubation systems, which have usually failed to reveal a fetal B cell response to glucose or other stimulatory factors [3].

\section{Materials and methods}

\author{
Animals \\ Three-month-old virgin female Sherman rats weighing about $250 \mathrm{~g}$ \\ were fed ad libitum with laboratory chow (U.A.R. B-03), and caged \\ overnight with a male (17.00-09.00 hours). Pregnancy was detected by \\ abdominal palpation 13 days later. In our colony, birth occurred
}


Table 1. Weight gain, plasma glucose and insulin concentrations in control and glucose-infused pregnant rats

\begin{tabular}{llll}
\hline & $\begin{array}{l}\text { Weight gain } \\
\text { during the pe- } \\
\text { riod of infusion } \\
(\mathrm{g})\end{array}$ & $\begin{array}{l}\text { Plasma glucose } \\
\text { concentration } \\
(\mathrm{g} / \mathrm{l})\end{array}$ & $\begin{array}{l}\text { Plasma insulin } \\
\text { concentration } \\
(\mu \mathrm{U} / \mathrm{ml})\end{array}$ \\
\hline $\begin{array}{l}\text { Control rats } \\
(n=14)\end{array}$ & $45.3 \pm 11.1$ & $0.79 \pm 0.02$ & $117 \pm 11$ \\
$\begin{array}{l}\text { Slightly } \\
\text { hyperglycaemic } \\
\text { rats } \\
(n=12)\end{array}$ & $36.8 \pm 7.1$ & $1.45 \pm 0.05^{\mathrm{a}}$ & $353 \pm 83^{\mathrm{a}}$ \\
$\begin{array}{l}\text { Highly } \\
\text { hyperglycaemic } \\
\text { rats } \\
(n=14)\end{array}$ & $34.1 \pm 10.2$ & $3.52 \pm 0.30^{\mathrm{a}, \mathrm{b}}$ & $603 \pm 112^{\mathrm{a}, \mathrm{c}}$ \\
\hline
\end{tabular}

Values are means \pm SEM. The number of observations is indicated in parentheses. Significant differences between control and glucose-infused rats, ${ }^{a} p<0.001$; between slightly and highly hyperglycaemic rats, ${ }^{b} p<0.001,{ }^{\circ} p<0.01$

22 days after mating. Infusion of glucose was performed using the flexible technique for long-term infusions in unrestrained rats developed by Nicolaidis et al. [12].

Rats were fitted with an intracardiac catheter on day 13 of pregnancy. The infusion period began on day 15 of pregnancy and lasted until the removal of the fetuses. Hypertonic $(30 \%)$ sterile glucose (Chaix et Dumarais, Paris, France) was infused at an initial rate of $30 \mu \mathrm{l} / \mathrm{min}$ to produce slight hyperglycaemia or at a rate of $50 \mu \mathrm{l} / \mathrm{min}$ to produce marked hyperglycaemia. When necessary, infusion rates were slightly modulated throughout the period of infusion to maintain glycaemia in the desired ranges. Controls were infused with sterile distilled water (Chaix et Dumarais). Distilled water was chosen rather than isotonic saline to avoid sodium overload in controls. Since the rate of infusion was very slow compared with the blood flow rate in the superior vena cava, haemolysis was unlikely and not observed.

\section{Samples}

A semi-quantitative method (Haemoglukotest, Boehringer, Mannheim, FRG) was used twice daily to measure plasma glucose of infused pregnant rats on blood samples collected from the tail vein.

On day 21.5 of pregnancy, the pregnant rats were killed by cervical dislocation and the fetuses immediately exteriorised after Caesarean section. Blood was collected rapidly from the axillary vessels, centrifugated and plasma glucose concentration determined. Pancreases were dissected out and minced in pieces of approximately $0.5 \mathrm{~mm}^{3}$ using a tissue chopper (McIlwain, Gomshall, UK) and washed in a gassed Krebs-Ringer bicarbonate buffer (in mmol/1: $\mathrm{Cl}^{-}, 123 ; \mathrm{Na}^{+}$, $121 ; \mathrm{K}^{+}, 5.2 ; \mathrm{Ca}^{++}, 2.5 ; \mathrm{Mg}^{++}, 1.2 ; \mathrm{H}_{2} \mathrm{PO}_{4}^{-}, 1.2 ; \mathrm{HCO}_{3}^{-}, 25 ; \mathrm{SO}_{4}^{--}$, 1.2) containing $2.2 \mathrm{mmol} / 1$ glucose and $0.5 \%$ bovine serum albumin (Albumin, bovine, fraction V, fatty acid free, Sigma, St. Louis, Mo. USA).

\section{Experimental procedure}

The perifusion was performed according to the method of Kikuchi et al. [13] as described previously [5, 9]. Briefly, minced tissues from 2 or 3 fetuses of the same litter were placed into the perifusion chambers. The KRB buffer continuously gassed with $95 \% \mathrm{O}_{2}$ and $5 \% \mathrm{CO}_{2}$ $\left(\mathrm{pH}=7.4 ; 37^{\circ} \mathrm{C}\right)$ containing bovine serum albumin and $2.2 \mathrm{mmol} / 1$ glucose was driven at a flow rate of $0.8 \mathrm{ml} / \mathrm{min}$ to the perifusion chambers. A fraction collector was used for the collection of the effluent. The temperature of the chambers and of the flasks was kept at $37^{\circ} \mathrm{C}$ in a water bath.
A stabilization period of $108 \mathrm{~min}$ with the basal medium preceded the stimulatory period ( $40 \mathrm{~min})$. The effluent of the last $12 \mathrm{~min}$ of the stabilization period was collected every $2 \mathrm{~min}$, and the samples obtained during this period were used for the determination of the basal rate of insulin release.

The rate of insulin secretion from the pancreatic pieces was expressed as $\mu U$ insulin: $\min ^{-1} \cdot \mathrm{mg}$ pancreas ${ }^{-1}$.

After the perifusion procedure, the pieces of pancreas were recovered, weighed and insulin extracted in $1 \mathrm{ml}$ of acid-alcohol solution (ethanol $75 \%$, distilled water $23.5 \%, 13 \mathrm{~N}$ hydrochloric acid $1.5 \%$ ) by ultrasonic desintegration at $4^{\circ} \mathrm{C}$ during $30 \mathrm{~s}$. Extracts were centrifugated and the supernatant kept at $-20^{\circ} \mathrm{C}$ until assay.

\section{Assays}

Plasma glucose was determined by the glucose oxidase technique using a glucose analyzer (Beckman, Palo Alto, Calif. USA).

Immunoreactive insulin (IRI) was estimated using purified rat insulin as standard (R 171, Novo, Copenhagen, Denmark), antibody to a mixture of porcine and bovine insulin [15] and porcine monoiodinated ${ }^{125}$ I-insulin [16] Silicate was used to separate free from bound hormone [15]. The method allowed the determination of $6 \mu \mathrm{U} / \mathrm{ml}$ $(0.25 \mathrm{ng} / \mathrm{ml})$ with a within and between assay coefficient of variation of $10 \%$.

\section{Statistical analysis}

Results are expressed as means \pm SEM. Significance of differences between means as evaluated by Student's unpaired t-test.

\section{Results}

The different flow rates of glucose infusion allowed a clear separation of the three groups of pregnant rats. Plasma glucose concentration in slightly hyperglycaemic rats was maintained between $1.4 \mathrm{~g} / 1$ and $2 \mathrm{~g} / 1$ throughout the period of infusion, while it reached much higher values (more than $3 \mathrm{~g} / \mathrm{l}$ ) in highly hyperglycaemic rats. Blood glucose concentrations in controls were always maintained between $0.8 \mathrm{~g} / 1$ and $1 \mathrm{~g} / 1$. The precise measure of plasma glucose concentration in pregnant rats on the day of delivery confirmed these data (Table 1).

Hyperglycaemia led to increased plasma insulin levels in both groups of glucose-infused rats; the levels were more pronounced in highly hyperglycaemic rats (Table 1). Infusion with glucose did not induce a significant change in weight gain of pregnant rats (Table 1). As expected, plasma glucose concentration was significantly higher in fetuses from slightly $(1.11 \pm 0.09 \mathrm{~g} / 1)$ or highly $(2.86 \pm 0.15 \mathrm{~g} / 1)$ hyperglycaemic rats than in controls $(0.49 \pm 0.01 \mathrm{~g} / 1)$.

\section{Insulin release by perifused fetal pancreases in vitro}

In the three experimental groups, insulin release by perifused fetal pancreases was initially very high. It fell rapidly and continuously until $64 \mathrm{~min}$. Thereafter, a stabilized baseline was obtained. In fetuses from highly hyperglycaemic mothers, insulin secretion rates stabilized more rapidly than in the two other groups; a pla- 


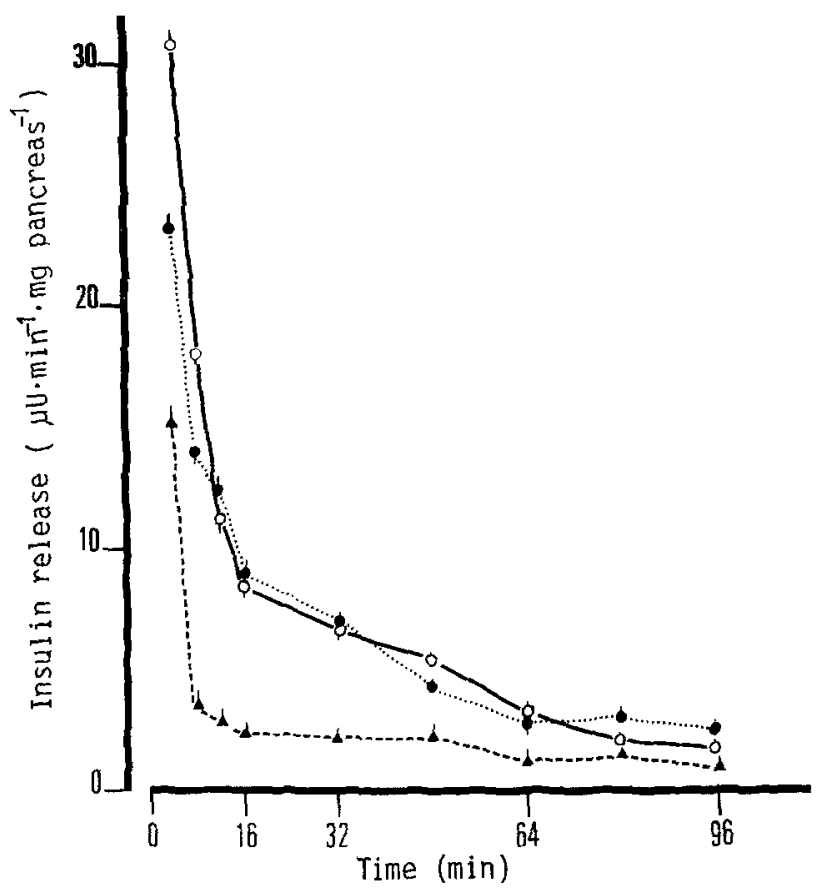

Fig. 1. Insulin release by minced pancreases from control $(0-0)$, slightly hyperglycaemic $(\cdots \cdots)$, or highly hyperglycaemic ( $A$ - - A ) fetuses during the prestimulatory period with KRB$2.2 \mathrm{mmol} / \mathrm{l}$ glucose. Results represent the mean of 38 (control), 36 (slightly hyperglycaemic fetuses), 40 (highly hyperglycaemic) fetus observations
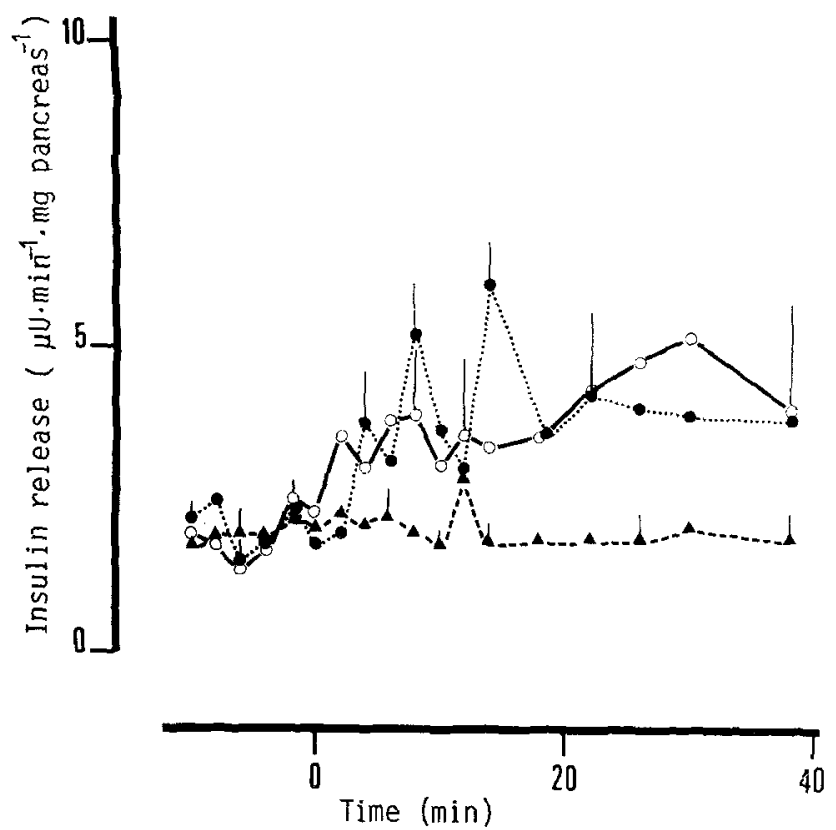

Fig. 2. Effect of $10 \mathrm{mmol} / 1$ leucine added to the KRB- $2.2 \mathrm{mmol} / \mathrm{lglu}$ cose medium on insulin release by minced pancreases from control $(\mathrm{O}-\mathrm{O})$, slightly hyperglycaemic $(\cdots \cdots)$, or highly hyperglycaemic ( $40 \mathrm{~min}$. Number of observations: 7 for control fetuses, 8 for slightly hyperglycaemic fetuses, 8 for highly hyperglycaemic fetuses

teau was observed from $16 \mathrm{~min}$ (Fig. 1). After reaching a stable baseline, insulin release during the prestimulatory period was similar in all groups of fetuses (Figs. 2-6; Table 2).

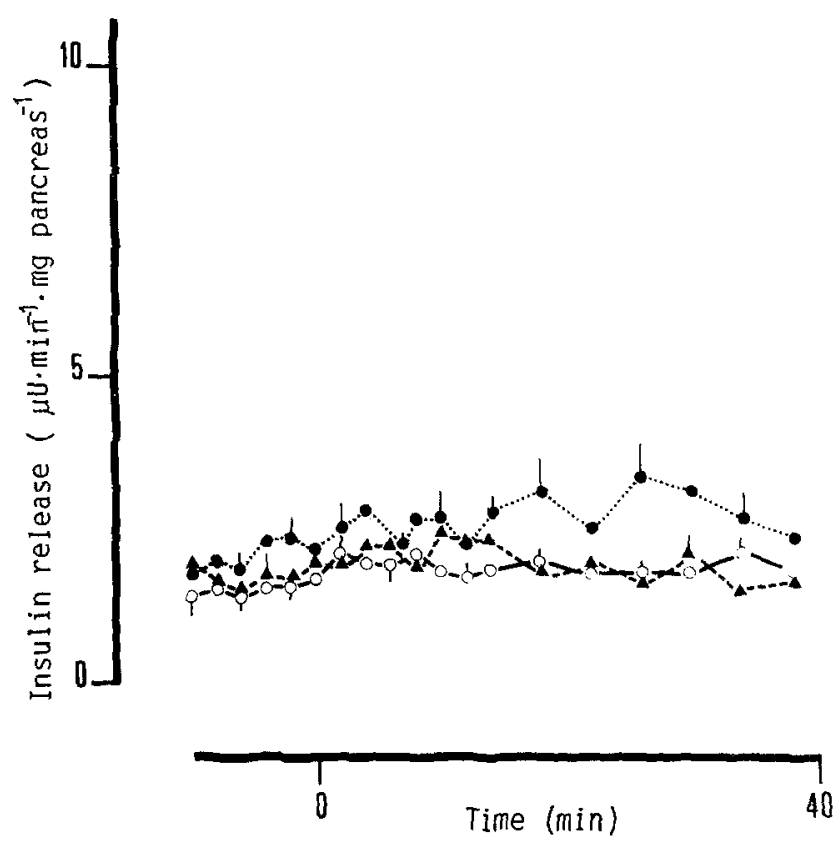

Fig. 3. Effect of $5 \mathrm{mmol} / 1$ glyceraldehyde on insulin release by pieces of pancreas from control $(\mathrm{O}-\mathrm{O})(n=11)$, slightly $(-\cdots)(n=6)$, or highly hyperglycaemic $(\boldsymbol{A}-\ldots)(n=6)$ fetuses. $n=$ number of cases. The experimental procedure was identical to that used for leucine
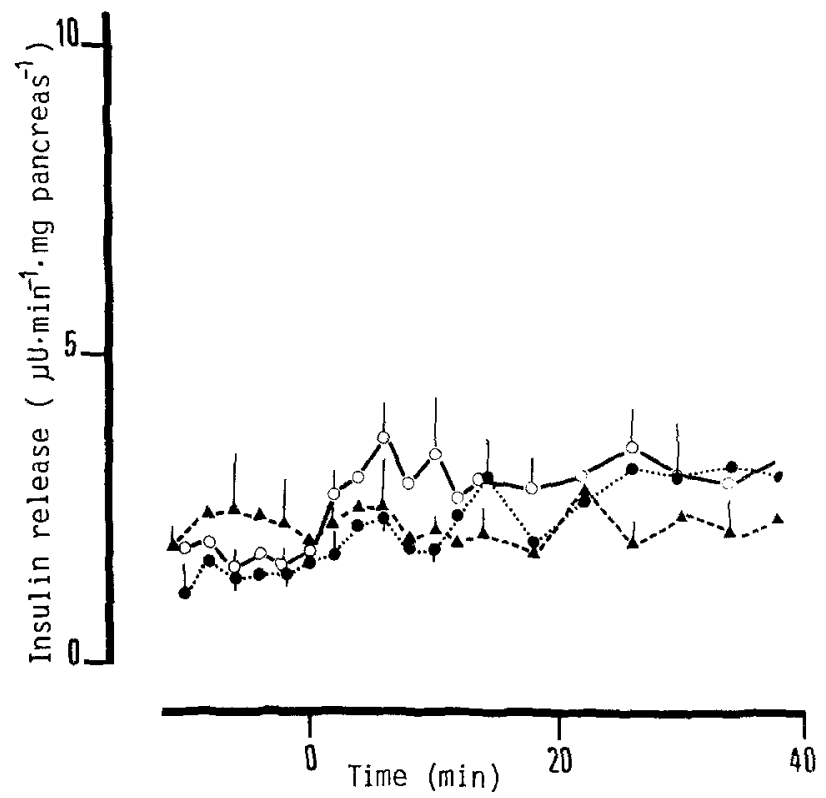

Fig.4. Insulin secretory response to $10 \mathrm{mmol} / 1 \alpha$-keto-isocaproïc acid of pieces of pancreas from control $\left(\mathrm{O}_{-} \mathrm{O}\right)(n=8)$, slightly hyperglycaemic $(\cdots \cdots)(n=6)$, or highly hyperglycaemic fetuses $(\Delta \cdots \wedge)(n=6) . n=$ number of observations

Insulin secretory response to $10 \mathrm{mmol} / 1$ leucine was similar in fetuses from control and slightly hyperglycaemic rats; i.e. a two-fold increase of insulin release was observed in the presence of this secretagogue. It was un- 
able to induce any increase above the basal insulin secretion in fetuses from highly hyperglycaemic rats (Fig. 2; Table 2).

Regardless of experimental group, neither $5 \mathrm{mmol} / 1$ glyceraldehyde nor $10 \mathrm{mmol} / 1 \mathrm{KlC}$ noticeably stimulated insulin secretion by pieces of fetal pancreas (Fig. 3; Table 2) $(p<0.2)$.

The medium containing $20 \mathrm{mmol} / 1$ arginine had a potent stimulatory effect on insulin release by pancreases from control and slightly hyperglycaemic fe-

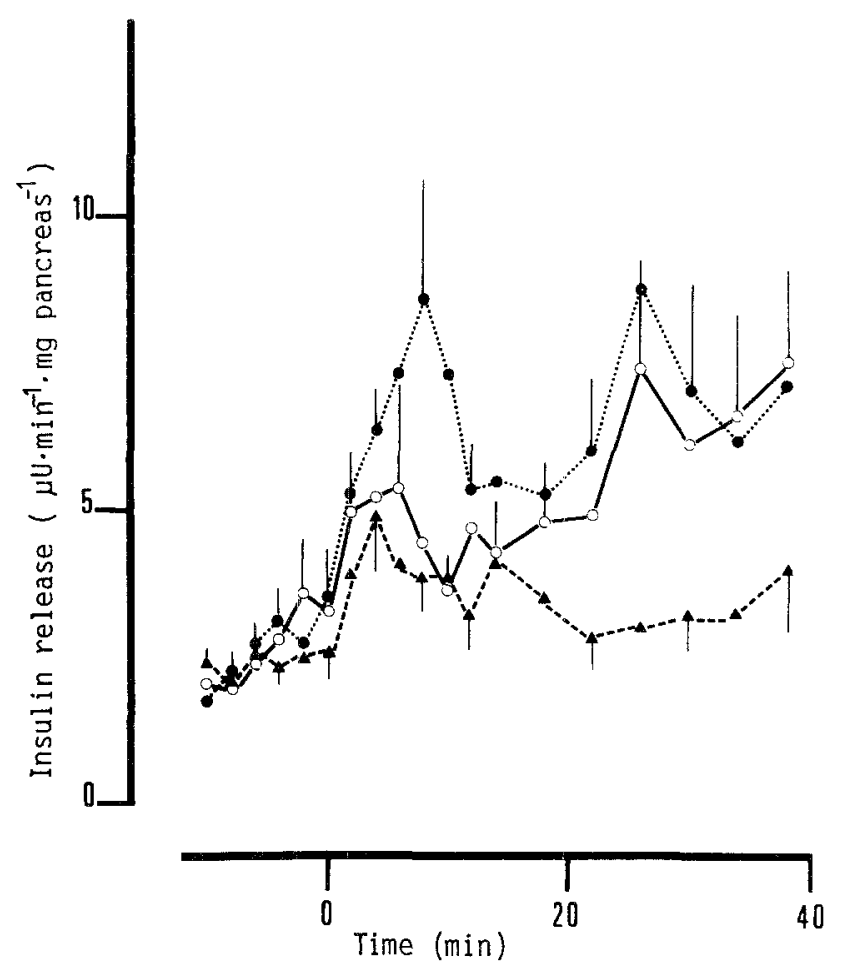

Fig.5. Effect of $20 \mathrm{mmol} / 1$ arginine on insulin release by pieces of pancreas from control $(\mathrm{O}-\mathrm{O})(n=12)$, slightly hyperglycaemic

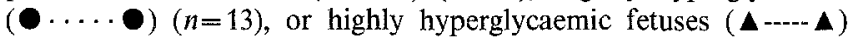
$(n=20)$. Arginine was added to the basal medium (KRB $2.2 \mathrm{mmol} / \mathrm{l}$ glucose) at 0 min. $n=$ number of cases tuses. This effect was even more marked in the latter group, in which the rate of insulin secretion in response to arginine was significantly higher than in controls $(p<0.01)$. In highly hyperglycaemic fetuses, $20 \mathrm{mmol} / 1$ arginine elicited a sustained increase of insulin secretion, although it was lower than in the other two groups. A clear-cut early phase of insulin secretion, could be observed the magnitude of which was similar to that of controls (Fig. 5; Table 2).

It may be noted that the pattern of insulin release by pieces of fetal pancreas appeared to be different according to the potency of secretagogues: $20 \mathrm{mmol} / 1$ arginine which had a powerful effect on insulin secretioninduced biphasic insulin release, while less effective secretagogues such as $10 \mathrm{mmol} / 1$ leucine elicited insulin secretory responses which could not be clearly separated into two phases. Hence in order to homogenize the expression of the results, the rate of insulin release was estimated during the whole stimulatory period, regardless of insulin secretion pattern.

Insulin content of the pancreases, as measured at the end of the perifusion period, was significantly higher in slightly hyperglycaemic fetuses (3.62 \pm

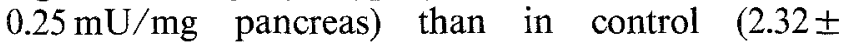
$0.35 \mathrm{mU} / \mathrm{mg}$ pancreas) and highly hyperglycaemic fetuses $(2.63 \pm 0.29 \mathrm{mU} / \mathrm{mg}$ pancreas $)(p<0.01)$. No significant difference was observed between the two latter groups.

\section{Discussion}

The high initial insulin release we observed in all groups of fetuses (but to a lesser degree in highly hyperglycaemic fetuses) has also been reported by other investigators using the same technique $[13,14]$. It is usually considered to be largely artifactual and related to non-specific insulin release by $\mathrm{B}$ cells injured by the section of the pancreas. Pancreatic insulin concentration at the

Table 2. Insulin release by perifused pancreases of control, slightly hyperglycaemic, or highly hyperglycaemic fetuses in response to 5 mmol/1 glyceraldehyde, $20 \mathrm{mmol} / \mathrm{l}$ arginine, $10 \mathrm{mmol} / \mathrm{l}$ leucine, or $10 \mathrm{mmol} / \mathrm{l}$. $\alpha$-keto-isocaproic acid (KIC)

\begin{tabular}{|c|c|c|c|c|c|c|c|c|c|}
\hline & \multicolumn{6}{|c|}{ Insulin release $\left(\mu \mathrm{U} \cdot \mathrm{min}^{-1} \cdot \mathrm{mg}\right.$ of pancreas $\left.{ }^{-1}\right)$} & \multicolumn{3}{|c|}{$\%$ of basal rate } \\
\hline & \multicolumn{3}{|c|}{$\begin{array}{l}\text { Prestimulatory phase (min) } \\
(-12-0)\end{array}$} & \multicolumn{3}{|c|}{$\begin{array}{l}\text { Stimulatory phase (min) } \\
(0-40)\end{array}$} & Controls & $\mathrm{SH}$ & $\mathrm{HH}$ \\
\hline $\begin{array}{l}\text { Glyceraldehyde } \\
(5 \mathrm{mmol} / \mathrm{l})\end{array}$ & $\begin{array}{l}1.45 \pm 0.13 \\
(11)\end{array}$ & $\begin{array}{l}2.16 \pm 0.44 \\
(6)\end{array}$ & $\begin{array}{l}1.69 \pm 0.34 \\
(6)\end{array}$ & $\begin{array}{l}1.79 \pm 0.21 \\
(11)\end{array}$ & $\begin{array}{l}2.58 \pm 0.33 \\
(6)\end{array}$ & $\begin{array}{l}1.95 \pm 0.23 \\
(6)\end{array}$ & $\begin{array}{l}123 \\
(11)\end{array}$ & $\begin{array}{l}120 \\
(6)\end{array}$ & $\begin{array}{l}120 \\
(6)\end{array}$ \\
\hline $\begin{array}{l}\text { Leucine } \\
(10 \mathrm{mmol} / 1)\end{array}$ & $\begin{array}{l}2.15 \pm 0.51 \\
(5)\end{array}$ & $\begin{array}{l}1.59 \pm 0.62 \\
(5)\end{array}$ & $\begin{array}{l}1.99 \pm 0.33 \\
(6)\end{array}$ & $\begin{array}{l}4.05 \pm 0.68 \\
\text { (5) } \mathrm{c}\end{array}$ & $\begin{array}{l}3.93 \pm 0.94 \\
\text { (5) } \mathrm{c}\end{array}$ & $\begin{array}{l}1.94 \pm 0.26 \\
(6) \mathrm{b}\end{array}$ & $\begin{array}{l}188 \\
(5)\end{array}$ & $\begin{array}{l}202 \\
(5)\end{array}$ & $\begin{array}{l}102 \\
(6)\end{array}$ \\
\hline $\begin{array}{l}\text { KIC } \\
(10 \mathrm{mmol} / \mathrm{l})\end{array}$ & $\begin{array}{l}1.95 \pm 0.27 \\
(8)\end{array}$ & $\begin{array}{l}1.57 \pm 0.37 \\
(6)\end{array}$ & $\begin{array}{l}2.35 \pm 0.48 \\
(5)\end{array}$ & $\begin{array}{l}3.01 \pm 0.47 \\
(8)\end{array}$ & $\begin{array}{l}2.63 \pm 0.77 \\
(6)\end{array}$ & $\begin{array}{l}2.19 \pm 0.46 \\
(5)\end{array}$ & $\begin{array}{l}154 \\
(8)\end{array}$ & $\begin{array}{l}167 \\
(6)\end{array}$ & - \\
\hline
\end{tabular}

SH: slightly hyperglycaemic fetuses; HH: highly hyperglycaemic fetuses; number of cases in parentheses. Values are means \pm SEM; the average rates of insulin release were calculated from data shown in Figures $2-5$. Significant differences between control and $\mathrm{SH}$ or $\mathrm{HH}$ fetuses, ${ }^{a} p<0.05$; ${ }^{\mathrm{b}} p<0.01$. Significant differences between basal and stimulated insulin release, ${ }^{\mathrm{c}} p<0.05 ;{ }^{\mathrm{d}} p<0.001$ 
end of the perifusion, which was much higher than insulin release during the perifusion, was not decreased in highly hyperglycaemic fetuses compared with controls. Thus, lowered insulin secretion in the prestationary phase by pancreases of highly hyperglycaemic fetuses compared with the two other groups can hardly be supposed to reflect a decrease of insulin storage.

Many authors have suggested that insulin secretory response to amino acids is present in the rat fetus at term, but is greatly attenuated compared to the adult one $[4,5,17]$. In the present study, leucine elicited a discrete but significant increase in insulin release in control and slightly hyperglycaemic fetuses; however, the pattern of the response was not clearly biphasic. On the basis of in vivo and in vitro experiments (static incubation systems), leucine was reported to be poorly effective in insulin release by islets of 1-day-old rats [4]. Increment of insulin secretion in response to the mixture leucine + arginine by fetal rat pancreases was shown by Rothen [3]; however, in this report, the effect of leucine alone was not emphasized.

In the adult rat, D-glyceraldehyde, which enters glycolytic pathway at the triose phosphate step, and $\alpha$-ketoisocaproic acid, the first catabolic product of leucine, have a potent stimulatory effect on insulin secretion [18, 19]. To our knowledge, the insulin secretory response of the fetal rat pancreas to $\alpha$-ketoisocaproic acid has not been previously investigated. The effect of glyceraldehyde on this secretion remains controversial. Agreen et al. [20] showed a slight but significant effect of glyceraldehyde on insulin secretion, whereas Grill et al. [4] found no significant effect. We failed to demonstrate any response of insulin release to D-glyceraldehyde in all groups of fetuses; on the other hand, $\alpha$-ketoisocaproic acid had a poor stimulatory effect on insulin secretion in control and slightly hyperglycaemic fetuses, and was completely ineffective in highly hyperglycaemic fetuses. Although it cannot be excluded that these negative results could be ascribed to blunted permeability of the fetal B cell in vitro, these data suggest that the attenuated insulin secretory response to glucose and leucine observed in the fetus may result from the poor metabolism of these nutrients in fetal islets. Recent findings of unchanged NADP ${ }^{+} / \mathrm{NADPH}$ ratios [21], potassium efflux and calcium uptake [22] by increased glucose concentration within the fetal islets support this point of view.

Arginine, which is not metabolized within the islet and depolarizes $B$ cells without decreasing the permeability to potassium, in contrast with glucose and leucine [23], sharply stimulated insulin secretion by pancreases of control fetuses. Rhoten [3] also reported a potent stimulatory effect of arginine on insulin secretion by pancreata of 20-day-old fetuses in vitro; however, in this study, the response was monophasic. This slight discrepancy with our results may be attributed to the lower dose of arginine used in his study $(10 \mathrm{mmol} / \mathrm{l})$ compared to our study $(20 \mathrm{mmol} / \mathrm{l})$. On the basis of in vivo experiments, it has also been reported that the human fetal pancreas might respond to arginine very early in gestation and that the response might be of a high magnitude in the fetus at term [24, 25]. The arginine-induced insulin release by the pancreas of slightly hyperglycaemic fetuses was significantly enhanced compared with that of controls. Similarly, it has been shown that human newborns from gestationally diabetic mothers responded to arginine infusion with a greater and more sustained rise of plasma insulin than newborns from normal women [25]. The synergistic effects of glucose and arginine upon insulin release has been demonstrated in premature infants [26] and in adult men [27, 28] or rats [29]. Our results show that sustained slight gestational hyperglycaemia potentiates the insulin response to arginine in the fetal rat at term.

Insulin secretion was always lower in highly hyperglycaemic fetuses than in control and slightly hyperglycaemic fetuses. However, differentiated severity of the alteration could be observed according to the nature of the secretagogue. In a previous study, insulin release was insensitive to glucose alone or associated with theophylline in these fetuses [9]. In the present study, inhibited responsiveness to leucine of pancreas from highly hyperglycaemic fetuses demonstrates that altered insulin response is not limited to glucose but can be extended to other nutrient secretagogues. In contrast, although lower than in slightly hyperglycaemic fetuses, a sustained but monophasic insulin secretory response to arginine was observed in highly hyperglycaemic fetuses. Taken together with the finding that pancreatic insulin storage was not different from that of controls, this strongly suggests that the defect may concern the stimulus-secretion coupling rather than the insulin releasing machinery, which is probably in other respects intact.

Our experimental model allows the production of well-controlled hyperglycaemia and avoids other main metabolic disorders associated with diabetes [30]. Therefore, the findings reported here suggest that the level of gestational glycaemia, independent of other environmental factors or toxic injuries, is of crucial importance in the further insulin secretory responsiveness to both glucose and amino acids. It may especially affect the maturation of the stimulus-secretion coupling mechanism in the $\mathrm{B}$ cell.

Acknowledgments. The authors express their gratitude to M.F. Kinebanyan for very expert technical assistance. They are indebted to $\mathrm{Dr}$ A. Kervran, CNRS-INSERM-34033, for helpful advice concerning the perifusion procedure and to Dr G. Rosselin, INSERM U.55, for the gift of iodinated-insulin. This work was supported in part by a grant from the Institut National de la Santé et de la Recherche Médicale (INSERM - Contrat de Recherche No. 857010).

\section{References}

1. Obenshain SS, Adam PAJ, King KC, Teramo K, Raivo KO, Raiha $\mathrm{N}$, Schwartz R (1970) Human fetal insulin response to sustained maternal hyperglycaemia. N Engl J Med 283: 566-570 
2. Phelps RL, Freinkel N, Rubinstein AH, Kuzunga H, Metzger B, Boëhm JJ, Mölsted-Pedersen L (1978) Carbohydrate metabolism in pregnancy. XV Plasma C-peptide during intravenous glucose tolerance in neonate from normal and insulin-treated diabetic mothers.

3. Rhoten WB (1980) Insulin secretory dynamics during development of rat pancreas. Am J Physiol 239: E57-E63

4. Grill V, Lake W, Freinkel N (1981) Generalized diminution in response to nutrients as insulin releasing agents during the early neonatal period in the rat. Diabetes $30: 56-63$

5. Kervran A, Guillaume M, Jost A (1978) The endocrine pancreas of the fetus from diabetic pregnant rat. Diabetologia 15: 387-393

6. Steinke $J$ and Driscoll SG (1965) The extractable insulin content of pancreas from fetuses and infants of diabetic and control mothers. Diabetes 14: 573-581

7. Farquhar JW (1969) Infant of diabetic mother. Postgrad Med J 45: 806-811

8. Aerts L and Van Assche FA (1977) Rat foetal endocrine pancreas in experimental diabetes. J Endocrinol 73: 339-346

9. Bihoreau MT, Ktorza A, Kervran A, Picon L (1986) Effect of gestational hyperglycemia on insulin secretion in vivo and in vitro by fetal rat pancreas. Am J Physiol (in press)

10. Gylfe E, and Sehlin JO (1976) Interactions between the metabolism of L-leucine and D-Glucose in the pancreatic B-cells. Horm Metab Res 8: 7-11

11. Hellman B, Sehlin J and Taljedal I (1971) Effects of glucose and other modifiers of insulin release on the oxidative metabolism of amino acids in microdissected pancreatic islets. Biochem $\mathrm{J} 123$ : $513-521$

12. Nicolaïdis S, Rowland N, Meile M, Marfaing-Jallat P and Pesez A (1974) A flexible technique for long-term infusions in unrestrained rats. Pharmacol Biochem Behav 2: 131-136

13. Kikuchi M, Blakard WG, Renold AE (1974) Perifusion of pancreas fragments: a system for study of the dynamic aspects of insulin secretion. Diabetes 23: $550-559$

14. Kervran A and Randon J (1980) Development of insulin release by fetal pancreas in vitro. Effects of glucose, amino acids, and theophylline. Diabetes 29:673-678

15. Rosselin G, Assan R, Yalow RS, Berson SA (1966) Separation of antibody bound and unbound peptides hormones with iodine ${ }^{131}$ by talcum powder and precipitated silica. Nature 212: 355-357

16. Freychet P, Roth J, Neville DM Jr (1971) Monoiodo insulin: demonstration of its biological activity and binding to fat cells and liver membranes. Biochem Biophys Res Commun 43: 400-408

17. Heinze E and Steinke J (1972) Insulin secretion during development: response of isolated pancreatic islets of fetal, newborn and adult rats to theophylline and arginine. Horm Metab Res 4: 234-236

18. Hellman B, Idahl LA, Lernmark A, Sehlin J, Taljedal IB (1974) The pancreatic B cell recognition of insulin secretagogues. Comparison of glucose with glyceraldehyde isomers and dihydroxyacetone. Arch Biochem Biophys 162: 448-457
19. Giroix MH, Portha B, Kergoat M, Bailbe D, Picon L (1983) Glucose insensitivity and amino acid hypersensitivity of insulin release in rats with non-insulin dependent diabetes. Diabetes 32 : 445-451

20. Agren A, Andersson A, Hellerström C (1976) Effects of D-glyceraldehyde and D-glucose on the insulin release of pancreatic islets isolated from the newborn rat. FEBS Lett 17(1): 185-188

21. Ammon HPT, Bumiller G, Düppenbecker H, Heinze E, Lutz S, Verspohl EJ (1983) Pentose phosphate shunt, pyridine nucleotides, glutathione, and insulin secretion of fetal islets. Am J Physiol 244: E354-E360

22. Ammon HPT, Fahmy A, Mark M, Strölin W, Wahl MA (1985) Failure of glucose to affect rubidium efflux and calcium uptake of fetal rat pancreatic islets. J Physiol 358: 365-372

23. Henquin JC and Meissner HP (1981) Effects of amino acids on membrane potential and ${ }^{86} \mathrm{Rb}+$ fluxes in pancreatic B-cell. Am J Physiol 240: E245-E252

24. Milner RDG, Ashworth MA, Barson AJ (1972) Insulin release from human fetal pancreas in response to glucose, leucine and arginine. J Endocrinol 52: 497-505

25. King KC, Adam PAJ, Yamaguchi K, Schwartz R(1974) Insulin response to arginine in normal newborn infants and infants of diabetic mothers. Diabetes $23: 816-820$

26. Grasso S, Messina A, Saporita N, Reitano G (1968) Serum-insulin response to glucose and amino acids in the premature infant. Lancet 2: $755-757$

27. Efendic S, Cerasi E, Luft R (1971) Role of glucose in arginine-induced insulin release in man. Metabolism 20:568-579

28. Nesher R, Tuch B, Hage C, Levy J, Cerasi E (1984) Time dependent inhibition of insulin release: suppression of the arginine effect by hyperglycemia. Diabetologia $26: 142-145$

29. Grill V, Adamson U, Rundfeldt M, Andersson S, Cerasi E (1979) Glucose memory of pancreatic $B$ and $A_{2}$ cells: evidence for common time dependent actions of glucose on insulin and glucagon secretion in the perfused rat pancreas. $J$ Clin Invest 64: 700-707

31. Ktorza A, Girard JR, Kinebanyan MF, Picon L (1981) Hyperglycaemia induced by glucose infusion in the unrestrained pregnant rat during the last three days of gestation: metabolic and hormonal changes in the mother and the fetuses. Diabetologia 21: $569-574$

Received: 3 September 1985

and in revised form: 12 May 1986

Dr. A. Ktorza

Laboratoire de Physiologie du Développement

associé au CNRS No.307

Tour 23-33, 1er étage

Université Paris VII

2, Place Jussieu

F-75251 Paris Cédex 05

France 